\title{
EMPATHY AND ITS FACTORS: EMPIRICAL STUDY
}

\author{
Dalia Antiniené1, Rosita Lekavičien $\dot{e}^{2}$ \\ Lithuanian University of Health Sciences ${ }^{1}$, Kaunas, Lithuania \\ Kaunas University of Technology², Kaunas, Lithuania
}

\begin{abstract}
Background. The level of personality's empathy largely determines altruistic behaviour and the quality of interpersonal relationships rendering the relevance of research indubitable. In psychology, empathy is classified into emotional/affective, cognitive and predictive. This study analyses affective empathy and aims to find out which personality traits related to self-perception, effectiveness in interpersonal relationships and sociodemographics are linked to empathy.

Methods. Research participants were schoolchildren, students, unemployed and employed individuals, inmates of imprisonment institutions and other young people. The target group was youth from 17 to 27 years of age, $M=19.7, N=1400$. An original measurement technique the psychometric quality indicators of which were sufficient (Cronbach's alpha reached .81) was used to research empathy.

Results. The means of Spearman's correlation coefficients revealed that empathy was related to self-irony $(r=.19, p \leq .001)$, externality $(r=.14 ; p \leq .05)$, positive self-evaluation $(r=.47 ; p \leq .001)$, leadership disposition $(r=.17 ; p \leq .05)$, etc. Mann-Whitney and Kruskal-Wallis tests revealed that women (Mean Rank $=274.88$ ) were more empathic than men (Mean rank $=139.78 ; p \leq .001$ ), young people with higher education (Mean Rank $=234.62$ ) were more empathic than those with no or some education (Mean Rank $=161.06 ; p \leq .001$ ), etc.

Conclusion. Research revealed that empathy was related to personal-psychological traits: self-irony, externality, positive self-evaluation, leadership disposition, general state of health, etc. The research highlighted the differences of empathy in different genders and revealed that women were more empathic than men. The research participants with high educational achievements exhibited the highest level of empathy.
\end{abstract}

Keywords: self-perception, interpersonal relationship effectiveness factors, sociodemographic factors.

\section{INTRODUCTION}

$\mathrm{R}$ elevance of research on personality and empathy is indubitable. It is an individual trait that often conditions altruistic behaviour, high-quality interpersonal relationships and aspirations to help people around. Thus, empathy plays a vital role in an individual's life as it allows the individual to interact effectively in social situations (Nanda, 2014). Range of researched questions is very wide - from whether it is a congenital or an acquired trait, to locating factors related to empathy.

The concept of empathy is treated rather ambiguously in psychology. The term, firstly used in the writings of an American psychologist E.
B. Titchener, was interpreted as motor mimicry (movement imitation) (Goleman, 2001). Later, the understanding of this concept was expanded. Currently, empathy may be defined as a deep feeling of another individual's emotional state (Psichologijos žodynas, 1993). According to Baron-Cohen (2011), empathy is an ability to identify what someone else is thinking or feeling and to respond to these thoughts and feelings with an appropriate emotion. Dictionary of Psychology (Psichologijos žodynas, 1993) indicates that we may talk not only about emotional empathy (based on the aforementioned mechanism of imitating affective reactions) and cognitive 
empathy (based on intellectual processes), but also about predictive empathy (ability to foresee affective reactions of a particular person in specific situations). Unfortunately, empathy researchers do not always clearly define how they perceive empathy, i.e. which component is central to their research. It must be acknowledged that certain confusion about concurrent concepts exists. For example, the concept of emotional intelligence is akin to empathy. As Mayer, Roberts, \& Barsade (2008) claim, the concept of emotional intelligence encompasses key aspects of empathy - especially that understanding of empathy which highlights the recognition of other individual's feelings. Some authors regard empathy as an undeniable indicator of high emotional intelligence and treat it as one of the components of EQ, e.g. one of the most famous research methodologies EI-i, TEIQue - includes empathy as a factor of EI (Bar-On \& Parker, 2000; Petrides, Furnham, \& Sanchez-Ruiz, 2008). However, these two concepts are not equivalent. Empathy differs from emotional intelligence by lower reflexivity and confinement to direct emotional experience, whereas emotional intelligence is always characterised by a pronounced cognitive component. In this study, empathy will be treated as compassion (empathising with feelings of others or with emotional states of others by identifying with them).

Even though many studies of empathy were conducted in order to find connections with demographic, personal and behavioural factors, their ambivalent results motivate scientists to delve further into this problem.

The purpose of this article was to present empirically validated relations between empathy, and self-perception, effectiveness of interpersonal relationships and sociodemographic factors among Lithuanian youth.

\section{METHODS}

Subjects. A total of 1400 subjects were interviewed. The target group involved young people from 17 to 27 years of age $(M=19.7, S D=3.29)$; $43.2 \%$ of men and $55.5 \%$ of women participated in the survey ( $1.3 \%$ have not specified their gender). A total of 1092 subjects who were studying were surveyed: 11-12th grade secondary school and gymnasium students $(n=371)$, vocational school $(n=384)$, college $(n=158)$ and university $(n=399)$ students. Other interviewees were the unemployed; imprisoned young people, representatives of some unions and social movements, and others.

\section{Instruments:}

- "Empathy" scale was comprised of 19 statements, e.g. "I am saddened when I see a lonely stranger surrounded by other people", "I become upset myself when I see a crying person", "Sometimes songs about love provoke many feelings", etc. Some statements were constructed in such a way that they needed to be transcoded in reverse order by giving evaluations of the opposite sign when calculating the study results. Subjects evaluated statements on a four-point scale from "Certainly not" to "Certainly yes" (coded as 0 to 3 in the data matrix). In the "empathy" scale $M=1.85$, $S D=0.41$ and $S E=0.02$. Psychometric quality of the "empathy" scale was tested: internal consistency index Cronbach's $\alpha$ was sufficiently high and equalled to .81, while resolution index $\mathrm{i} / \mathrm{tt}$ was always higher than .24.

- "Self-perception factors" block was comprised of three scales: 1) Locus of control scale: A scale of 16 statements was designed in order to determine properties of internality and externality. It was multiplexed into two factors of "internality" and "externality" using factor analysis. Calculated KMO index equalled to .79, both factors explain $34.70 \%$ of the general dispersion. Cronbach's $\alpha$ of "externality" and "internality" scales were respectively .75 and .65 , resolution index $\mathrm{i} / \mathrm{tt}$ varied from .32 to .53 and from .20 to .43 . Examples of statements in this scale: "Intelligence, will and work determine person's success, not fate or good connections", "I think that many events in my life take place by chance". Subjects evaluated statements on a six-point scale from 0 to 5 . In the "internality" scale $M=3.50, S D=0.68$ and $S E=0.03$; the "externality" scale $M=2.19, S D=0.82$ and $S E=0.04$. 2) Leadership scale: 13 statements reflecting person's leadership disposition were presented in this research instrument, e.g. "I enjoy demonstrating initiative and I am not afraid to suggest new ideas", "When surrounded by people I would not feel shy to start a discussion or express my opinion about something I know well if asked", etc. 
Subjects evaluated statements on a five-point scale from 0 to 4 . In the "leadership" scale $M=2.70, S D=0.53$ and $S E=0.03$. Internal consistency index was sufficiently good, Cronbach's $\alpha$ equalled to .80 ; resolution index $\mathrm{i} / \mathrm{tt}$ varied from .23 to .63. 3) Self-irony scale: It was comprised of five statements, e.g. "It would cause me a lot of laughter if I appeared in public wearing a sweater inside-out". Subjects evaluated statements on a scale from 0 to 5 . In the "self-irony" scale $M=3.25, S D=0.90$ and $S E=0.04$; internal consistency index Cronbach's $\alpha$ equalled to .79 , resolution index $\mathrm{i} / \mathrm{tt}$ varied from .46 to .65 , thus psychometric qualities of the scale were good. 4) Self-evaluation scale: 48 personality traits were presented, e.g. "brave", "bitter", and "understanding". Subjects were asked to evaluate whether these traits were characteristic of them on a scale from 0 to 6 . Traits clearly fell into two categories of factors reflecting positive and negative traits after factor analysis of the scale was completed; KMO index equalled to .86 , while both factors explained $28.80 \%$ of the general dispersion. In the "positive selfevaluation" subscale $M=4.32, S D=0.71$ and $S E=0.03$; in the "negative self-evaluation" subscale $M=2.93, S D=0.77$ and $S E=0.04$. Psychometric calculations revealed that in the "positive self-evaluation" subscale internal consistency index Cronbach's $\alpha$ equalled to .90 , resolution index $\mathrm{r} / \mathrm{itt}$ varied from .27 to .70 ; in the "negative selfevaluation" subscale Cronbach's $\alpha$ equalled to $.84, \mathrm{r} / \mathrm{itt}$ index varied from .20 to .59 .

- "Interpersonal relationship effectiveness factors" block was comprised of strategies of conflict resolution and extroversionintroversion scales. 1) Strategies of conflict resolution scale: 25 statements revealing the mode of behaviour in a conflict situation were evaluated on a scale from 0 to 5, e.g. "I put off contentious issues until situation calms down", "I can stand for myself". Factor analysis was used to multiplex statements into five subscales: "cooperation" $(M=3.35, S D=0.78, S E=$ $0.04)$, "compromise" $(M=3.36, S D=0.84$, $S E=0.04)$, "evasion" $(M=2.99, S D=0.86$, $S E=0.04)$, "adaptation" $(M=2.81, S D=0.72$, $S E=0.03)$ and "competition" $(M=2.55, S D=$ $0.82, S E=0.04)$. Internal consistency index Cronbach's $\alpha$ of these subscales varied from .67 to .75. 2) Extroversion - introversion scale was comprised of 19 statements that subjects evaluated on a scale from 0 to 4 . Examples of statements: "I feel strained and restless when I am in company", "I like to stand out using my appearance - clothes, hairstyle and similar", etc. In the "introversion" subscale $M=1.79, S D=0.66$ and $\mathrm{SE}=0.03$; in the "extroversion" subscale $M=2.45, S D=0.59$ and $S E=0.03$. Internal consistency indexes in these subscales were satisfactory, Cronbach's $\alpha$ varied from .67 to .70.

- "Sociodemographic factors" block was comprised of the following characteristics of a subject: gender, main activity, present occupation, etc. Questions about academic achievements of young people were also presented in this part of the questionnaire.

\section{RESULTS}

Correlation between personality's empathy and self-perception indexes demonstrated significant statistical relations (see Table 1) that differed by their strength and reliability. Especially strong and statistically significant relation was established between empathy and positive self-evaluation $(r=.47, p \leq .001)$. Weak, however statistically significant relation linked empathy and locus of control variable - externality. Also, a seldom strong connection was found with leadership and self-irony scales.

The study of empathy and interpersonal relationship effectiveness indexes also revealed many statistically significant relations. Since introversion and extroversion are opposite constructs and expressions, it is obvious that their relation with empathy, at least theoretically, should be opposite as

\begin{tabular}{|c|c|c|c|c|c|c|}
\hline & \multicolumn{6}{|c|}{ SCALES } \\
\hline & \multirow{2}{*}{ Leadership } & \multirow{2}{*}{ Self-irony } & \multicolumn{2}{|c|}{ Locus of control } & \multicolumn{2}{|c|}{ Self-evaluation } \\
\hline & & & Internality & Externality & Positive & Negative \\
\hline EMPATHY & $\begin{array}{c}17 \\
*\end{array}$ & $\begin{array}{l}19 \\
* *\end{array}$ & .17 & $\begin{array}{l}14 \\
*\end{array}$ & $\begin{array}{c}.47 \\
* * *\end{array}$ & .09 \\
\hline
\end{tabular}


well. Obtained results (see Table 2) confirmed this assumption: positive relation with extroversion and negative one with introversion were found.

Table 2 also demonstrates that empathic personalities tended to choose most peaceful conflict resolution strategies - cooperation, compromise and adaptation. These strategies were most closely related to ability to empathise with emotions of others ( $r$ varies from .35 to $.24, p \leq .001$ ).

Table 3 shows data of the importance of some sociodemographic factors to empathy. Statistically significant differences were established between males and females, different activity youth groups, inhabitants of different cities, some education indexes, e.g. well-educated youth (i.e. university, college, gymnasium students) were more empathic than less-educated youth (vocational school and secondary school students). Also, high-ability students demonstrated higher levels of empathy than low-ability students. It was found that subjects who were better at languages were more empathic than the ones studying hard sciences. Also,

Table 2. Correlation (Spearman's Correlation Coefficient) between empathy and interpersonal relationship effectiveness scales

\begin{tabular}{|c|c|c|c|c|c|c|c|}
\hline & \multicolumn{7}{|c|}{ SCALES } \\
\hline & \multirow{2}{*}{ Extroversion } & \multirow{2}{*}{ Introversion } & \multicolumn{5}{|c|}{ Conflict resolution strategies } \\
\hline & & & Cooperation & Compromise & Evasion & Adaptation & Competition \\
\hline EMPATHY & $\begin{array}{l}.31 \\
* * *\end{array}$ & $\begin{array}{c}-.16 \\
* *\end{array}$ & $\begin{array}{l}.35 \\
* * *\end{array}$ & $\begin{array}{l}.28 \\
* * *\end{array}$ & $\begin{array}{l}.18 \\
* *\end{array}$ & $\begin{array}{l}.24 \\
* * *\end{array}$ & -.07 \\
\hline
\end{tabular}

Note. ${ }^{*} \mathrm{p} \leq .05, * * \mathrm{p} \leq .01, * * * \mathrm{p} \leq .001$

Table 3. Relation between sociodemographic variables and empathy according to Mann-Whitney and Kruskal-Wallis, duplex model, $p \leq .05$

\begin{tabular}{|c|c|c|c|c|}
\hline \multirow{2}{*}{\multicolumn{2}{|c|}{ Sociodemographic variables }} & \multirow{3}{*}{$\begin{array}{c}\text { Mean Rank } \\
274.88 \\
139.78\end{array}$} & \multirow{3}{*}{$\begin{array}{c}\text { Asymp.Sig. } \\
\text { Kruskal-Wallis } \chi \mathbf{2} \\
p \leq .0001\end{array}$} & \multirow{3}{*}{$\begin{array}{c}\text { Mann-Whitney } U \\
\text { Kruskal-Wallis } \chi^{2} \\
846.4\end{array}$} \\
\hline & & & & \\
\hline Gender: & $\begin{array}{l}\text { Female } \\
\text { Male }\end{array}$ & & & \\
\hline Subject group: & $\begin{array}{l}\text { Professionals } \\
\text { Students of vocational schools }\end{array}$ & $\begin{array}{l}267.75 \\
161.06\end{array}$ & $p \leq .0001$ & 33.25 \\
\hline City of residence: & $\begin{array}{l}\text { Vilnius } \\
\text { Klaipedda }\end{array}$ & $\begin{array}{l}284.10 \\
165.74\end{array}$ & $p \leq .0001$ & 26.50 \\
\hline Evaluation of grades: & $\begin{array}{l}\text { High-ability student } \\
\text { Low-ability student }\end{array}$ & $\begin{array}{l}234.64 \\
160.96\end{array}$ & $p \leq .001$ & 14.88 \\
\hline Favourable subjects in school: & $\begin{array}{l}\text { Languages } \\
\text { Hard sciences }\end{array}$ & $\begin{array}{l}239.70 \\
184,99\end{array}$ & $p \leq .0001$ & 19.31 \\
\hline Field of study: & $\begin{array}{l}\text { Social sciences-humanities } \\
\text { Working-class professions }\end{array}$ & $\begin{array}{l}210.08 \\
116.21\end{array}$ & $p \leq .0001$ & 53.39 \\
\hline Level of education: & $\begin{array}{l}\text { High } \\
\text { Low }\end{array}$ & $\begin{array}{l}234.62 \\
161.06\end{array}$ & $p \leq .0001$ & 1111.65 \\
\hline
\end{tabular}

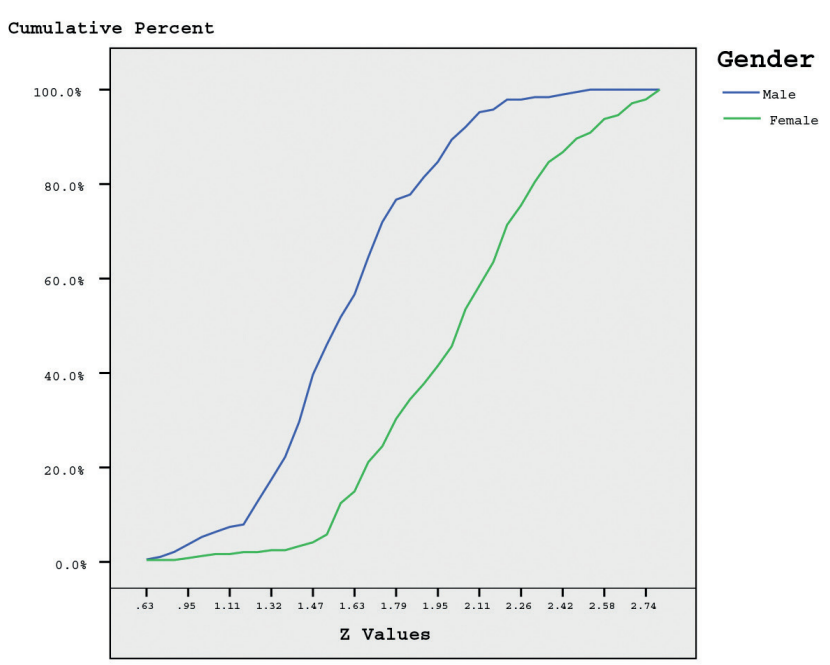

Figure. Comparison of empathy between males and females 
representatives of working-class professions were characterised by low empathy levels. Highest levels of empathy were manifested by young subjects who studied social sciences or humanities.

Figure demonstrates repeated comparison of empathy according to the gender of subjects. Cumulative percentage distribution was applied in order to compare the groups. Cumulative frequency curve informatively demonstrates the differences between these groups.

\section{DISCUSSION}

Empathy and self-perception. Hypothetically thinking, it was possible to assume that empathy was related to one of the dimensions of locus of control - internality, therefore this assumption was tested in this study.

Locus of control is a constant individual characteristic that forms during the process of socialisation. Personalities who possess external locus of control attribute responsibility to external forces, i.e. it is believed that their successes or failures are determined by external factors, whereas internal type personalities take responsibility for themselves, their own abilities and efforts. Interestingly, the study has revealed that empathy is more related to externality even though various studies demonstrate significant relations between internality and emotional intelligence of which empathy is a component (Antinienè and Lekavičiene, 2015; Bellamy, Gore \& Sturgis, 2005 (accepted for publication)). This discrepancy may be explained by the fact that in this study empathy was defined as compassion, i.e. empathising with the emotional states of others by identifying with them. This indicates lower reflexivity and imitation of affective reactions, whereas emotional intelligence is linked with cognitive empathy. It is therefore likely that empathic individuals are limited by direct emotional experience when perceiving a situation, while intellectual processes are not distinctly expressed. The latter feature is more characteristic of internal personalities. Nevertheless, relation established in the study was weak $(r=.14, p \leq .05)$.

No significantly stronger relation was found between empathy and leadership $(r=.17, \mathrm{p} \leq .05)$. Emotional dimension is very important to the idea of leadership. As James and Connolly (2000) note, all principles of leadership are based on the notion that the emotional level of leadership is the most important. According to Ryback (1998), successful leaders always adjusted in accordance with human interaction and their decisions were full of emotional sensitivity. Many empirical studies that found some sort of positive relations between the main emotional intelligence factors (empathy as one of them) and leadership potential were conducted (Batool, 2013; Esfahani \& Soflu, 2011; Hur, van den Berg, \& Wilderom, 2011; Lam \& O'Higgins, 2013). This study found statistically significant but not high correlation scores. It is likely that the scores would be higher if empathy was defined as a cognitive process and the study methodology was constructed accordingly.

Analysis of scientific literature has revealed that humour is associated with various psychological functions, interpersonal interaction, methods for combating stress, and psychological and social benefits (Martin, 2003; Yip \& Martin, 2006). On the other hand, not many studies analysing relations between emotional dimension and humour were conducted (Gignac, Karatamoglou, Wee, \& Palacios, 2014). Humour that is directed towards the joking person, i.e. self-irony is researched even more rarely. Therefore, it was interesting to evaluate such relation among empathic personalities. As many studies demonstrate, personalities with higher emotional competence are more likely to use humour to better social relationships without harm to themselves or others (Gignac et al., 2014). This study revealed that empathic personalities tended to make fun of themselves. It may be related to cultural environment and additional studies should be conducted to examine this hypothetical statement.

As various studies show, better emotional skills allow the personality to accept environment and themselves more positively, i.e. such individuals have higher self-evaluation levels (Lee, 2011; Petrides \& Furnham, 2006; Y1lmaz, Hamarta, Arslan, \& Deniz, 2013). Relations revealed by this study confirmed insights of other authors $-\mathrm{a}$ relative high correlation coefficient was established $(r=.47, p=.001)$. Positive attitude towards oneself allows the person to pay more emotional attention to others rather than to self-criticism and unproductive self-analysis.

Empathy and interpersonal relationship effectiveness. Success of interpersonal relationships of an individual may be conditioned by many various factors. This study researched two factors - extroversion/introversion of a personality and the choice of conflict resolution strategies. It is stereotypically usual to assume that self-oriented introverted 
individuals are able to experience emotions of themselves and others more effectively. Our study revealed a negative dependency, i.e. personality is less empathic as introversion features are more pronounced. However, correlation was not strong $(r=-.16, p \leq .01)$. On the contrary, empathy was demonstrated by extroverted-type individuals who under the stereotypical notion are more superficial in interpersonal relationships, inattentive to others and so on. Here, correlation was stronger $(r=.34$, $p \leq .001)$. Results of this study mirror the works of Ghiabia and Besharatb (2011), Johnson, Batey and Holdsworth (2009), and others. Some scientists explain better emotional skills of extroverts by claiming that information of emotional nature stimulates them, whereas introverts are affected by emotional information in an opposite way - disorganisation, misbalancing and so on (Rosete \& Ciarrochi, 2005, cited in Mayer et al., 2008). It is worthwhile noting that some studies found opposite results (Law, Wong, \& Song, 2004).

The empirical study revealed that empathic personalities demonstrated strategies of cooperation, compromise and adaptation when in conflict. It is obvious that all three strategies are oriented towards maintenance rather than destruction of the relationship. Other authors also agree that empathy is not related to aggressive competition strategy, for example, Lee (2011) found that empathy reduced and inhibited aggressive behaviours. On the other hand, studies show that individuals who score high in emotional intelligence are not afraid to choose the competition strategy, they do not anticipate in advance which strategy they will choose in conflict and are more likely to seek for a positive end to a conflict (Chan, Sit, \& Lau, 2014; Fernandez-Berrocal, Etremera, Lopes, \& Ruiz-Aranda, 2014). It is likely that the difference between the results arises due to the fact that emotional intelligence is associated with cognitive empathy, whereas this study analysed emotional empathy.

Empathy and sociodemographic factors. Higher levels of empathy among women are confirmed in this study as in many other studies, e.g. Hojat et al. (2002), Baron-Cohen \& Wheelright (2004) and so on. The most convincing evidence for gender differences in empathy is provided by studies using self-report measures to assess empathy (Rueckert, 2011). Results of some studies show that differences in empathy between genders may have a biological base. For example, Rueckert and Naybar (2008) investigated the relationship between activation of the right cerebral hemisphere (RH) and empathy. A correlation was found between $\mathrm{RH}$ activation on the face task and empathy for women only $(p=.037)$, suggesting a possible neural basis for gender differences in empathy. Earlier studies did not record differences of such type. For example, in their meta-analysis, Wager, Phan, Liberzon, \& Taylor (2003) did not find any significant difference in brain activity between men and women in response to emotional stimuli.

On the other hand, authors note that different results may be obtained depending on the methodology of a study. For example, data analyses revealed no significant gender differences in behavioural performance, but females rated themselves as more empathic than males in the self-report questionnaires (Derntl et al., 2010).

No other studies on the relation between empathy and quality of education among youth, high/low level of education and similar were located, but partial confirmation of some results may be found in the works of other authors. For example, Hojat et al. (2002) determined that personas' empathy significantly differed depending on their career, which may be oriented towards technology or people with higher levels of empathy among the latter (Wilks' lambda $=0.94$, related multivariate $\left.F_{(20,661)}=2.25, p<.01\right)$. This study revealed similar results: students of social sciences, humanities or those who were more successful when learning languages instead of hard sciences demonstrated higher levels of empathy.

Revealed fact that city inhabitants statistically significantly differ by their level of empathy is hard to interpret. According to Baron-Cohen (2011), culture and socialisation may play an important role in the development of empathy. Additional studies should be conducted to examine this statement.

\section{CONCLUSIONS}

The study has revealed that personality's empathy is related to various self-perception and interpersonal relationship effectiveness factors. More empathic subjects usually demonstrated more positive self-evaluation, better leadership skills, and familiarity with self-irony. Also, such individuals are more often extroverted and tend to attribute responsibility for events to external forces that do not depend on them. Such individuals usually choose strategies of cooperation, compromise and adaptation in order 
to resolve conflicts. All aforementioned relations are statistically significant even though correlation coefficients are not high (from .14 to .47).

This study has confirmed statistically significant relations between empathy and sociodemographic factors. The importance of gender to empathy was empirically proved: women scored higher than men. It was empirically proved that higher levels of empathy were manifested by high-ability students of social sciences and humanities.

\section{REFERENCES}

Antinienè, D., \& Lekavičienè, R. (2015). Emocinis intelektas: Lietuvos jaunimo tyrimas: monografija. Kaunas: Technologija (priimta spaudai).

Baron-Cohen, S., \& Wheelright, S. (2004). The empathy quotient: An investigation of adults with Asperger syndrome or high-functioning autism and normal sex differences. Journal of Autism and Developmental Disorders, 34, 163-175.

Baron-Cohen, S. (2011). Zero degrees of empathy: A new theory of human cruelty and kindness. London: Penguin.

Bar-On, R., \& Parker, J. D. A. (Eds.) (2000). The Handbook of emotional intelligence: Theory, development, assessment, and application at home, school, and in the workplace. San Francisco: JosseyBass.

Batool, B. F. (2013). Emotional intelligence and effective leadership. Journal of Business Studies Quarterly, 4(3), 84-94.

Bellamy, A., Gore, D., \& Sturgis, J. (2005). Examining the relevance of emotional intelligence within educational programs for the gifted and talented. Electronic Journal of Research in Educational Psychology, 6(3), 53-78. Retrieved from http://www. investigacion-sicopedagogica.org/revista/articulos/6/ english/Art_6_68.pdf

Chan, J. C. Y., Sit, E. N. M., \& Lau, W. M. (2014). Conflict management styles, emotional intelligence and implicit theories of personality of nursing students: A cross-sectional study. Nurse Education Today, 34, 934939.

Derntl, B. Finkelmeyer, A., Eickhoff, S. Kellermann, T., Falkenberg, D. Schneider, F. \& Habel, U. (2010). Multidimensional assessment of empathic abilities: Neural correlates and gender differences. Psychoneuroendocrinology, 35(1), 67-82. doi: 10.1016/j.psyneuen.2009.10.006

Esfahani, N., \& Soflu, G. H. (2011). Relationship between emotional intelligence and transformational leadership in physical education managers. ProcediaSocial and Behavioral Sciences, 30, 2384-2393.

Fernández-Berrocal, P., Etremera, N., Lopes, P. N., \& Ruiz-Aranda, D. (2014). When to cooperate and when to compete: Emotional intelligence in interpersonal decision-making. Journal of Research in Personality, 49, 21-24.

Ghiabia, B., \& Besharatb, M. A. (2011). An investigation of the relationship between personality dimensions and emotional intelligence. Procedia-Social and Behavioral Sciences 30, 416-420.

Gignac, G. E., Karatamoglou, A., Wee, S., \& Palacios, G. (2014). Emotional intelligence as a unique predictor of individual differences in humour styles and humour appreciation. Personality and Individual Differences, 56, 34-39.

Goleman, D. (2001). Emocinis intelektas. Vilnius: Presvika.

Hojat, M., Gonnella, J. S., Nasca, T. J., Mangione, S., Veloksi, J. J., \& Magee, M. (2002). The Jefferson scale of physician empathy: Further psychometric data and differences by gender and specialty at item level. Academic medicine, 77(10), 58-60.

Hur, J. H., van den Berg, P. T., \& Wilderom, C. P. M. (2011). Transformational leadership as a mediator between emotional intelligence and team outcomes. The Leadership Quarterly, 22(4), 591-603.

James, Ch., \& Connolly, U. (2000). Effective change in schools. London: Routledge Falmer.

Johnson, S. J., Batey, M., \& Holdsworth, L. (2009). Personality and health: The mediating role of Trait Emotional Intelligence and Work Locus of Control. Personality and Individual Differences 47, 470-475.

Lam, C.-S., \& O’Higgins, E. (2013). Emotional Intelligence and Leadership Styles in China. Asia Pacific Management Review, 18(4), 441-467.

Law, K. S., Wong, C., \& Song, L. (2004). The construct and criterion validity of emotional intelligence and its potential utility for management studies. Journal of Applied Psychology, 89, 483-496.

Lee, Ch.-J. (2011). Communication Competence, Empathy, and Self-Esteem. Journal of Humanities Therapy, 2, 83-94.

Martin, R. A. (2003). Sense of humor. In S. J. Lopez \& C. R. Snyder (Eds.), Positive psychological assessment: A handbook of models and measures (pp. 313-326), Washington, DC: American Psychological Association.

Mayer, J. D., Roberts, R. D., \& Barsade, S. G. (2008). Human abilities: emotional intelligence. Annual Review of Psychology. 59, 507-536.

Nanda, S. (2014). Are there Gender Differences in Empathy? Undergraduate Journal of Psychology, 7, Retrieved from http://ujpb.org/research/volume-7/arethere-gender-differences-in-empathy

Petrides, K. V., Furnham, A., \& Sanchez-Ruiz, M. J. (2008). TEIQue Development Report. Advanced People 
Strategies. Retrieved from: http://www.advancedpeoplestrategies.co.uk /files/ TEIQue $\% 20 \% 20$ Sample $\% 20$ Report.pdf

Petrides, K. V., \& Furnham, A. (2006). The role of trait emotional intelligence in a gender-specific model of organizational variables. Journal of Applied Social Psychology, 36, 552-569.

Psichologijos žodynas. (1993). Red. R. Augis, R. Kočiūnas. Vilnius: Mokslo ir enciklopedijų leidykla.

Rueckert, L. (2011). Gender differences in empathy. In Psychology of Empathy (pp. 221-234). Chicago, Illinois, USA: Illinois University.

Rueckert, L., \& Naybar, N. (2008). Gender differences in empathy: The role of the right hemisphere. Brain and Cognition, 67(2), 162-167.
Ryback, D. (1998). Putting emotional intelligence to work: Successful leadership is more than IQ. Boston: Butterwork-Heinemann.

Wager, T. D., Phan, K. L., Liberzon, I., \& Taylor, S. F. (2003). Valence, gender and lateralization of functional brain anatomy in emotion: A meta-analysis of findings from neuroimaging. NeuroImage, 19, 513-531.

Yilmaz, H., Hamarta, E., Arslan, C., \& Deniz, M. E. (2013). An investigation of loneliness, self-esteem and emotional intelligence skills in university students. International Journal of Academic Research Part B, 5(1), 205-209.

Yip, J. A., \& Martin, R. A. (2006). Sense of humor, emotional intelligence, and social competence. Journal of Research in Personality, 40, 1202-1208. 